\title{
Acid-base management - is it relevant for the study design of hypothermic neuroprotection?
}

Among the most important controversies in evidencebased medical science is the use of therapeutic hypothermia. Our knowledge about hypothermic brain protection is still limited and several crucial factors such as target brain temperature, start and duration of hypothermia treatment as well as various unknown others still remain to be explored. Recently, the use of therapeutic hypothermia from $32-34^{\circ} \mathrm{C}$ after cardiac arrest improved neurological outcome in an impressive way [1-3]. This was in contradiction to a large hypothermia trial (NABIS:H), funded by the National Institute of Health (NIH), [4] concerning brain injured patients - subjected to cooling - who failed to demonstrate any improved survival. Soon after publication of the latter study, some methodological aspects were criticised [5-7]. To improve the future accuracy of hypothermia studies, scientists are now being challenged to consider further factors which impact upon brain integrity during ischaemia and trauma $[8,9]$. Without doubt, among these are considerable changes in the relationship between cerebral blood flow (CBF) and metabolism.

Soon after therapeutic hypothermia was used to slow down metabolic rate of ischaemic tissue - and thereby to reduce the structural damage to tissues it become obvious that ' $\mathrm{pH}$ management' has an impact on outcome. Lung ventilation to normocapnia is temperature-dependent since the solubility of gases in blood is increased as temperature is lowered; the $\mathrm{pH}$ of arterial blood shifts in parallel to the neutral point of water towards alkalosis. If ' $\mathrm{pH}$-stat' management is used during hypothermia, the analytical results of the blood-gas analysis are corrected for the actual lower body temperature thus resulting in a more hypocapnic status. The compensatory reduction of lung ventilation increases the partial pressure of carbon dioxide and thereby augments CBF.

Correspondence to: Thomas Frietsch, Department of Anaesthesiology and Critical Care Medicine, Faculty of Clinical Medicine Mannheim, University of Heidelberg, Theodor Kutzer Ufer 1-3, D-68167 Mannheim, Germany. E-mail: bv3@ix.urz.uni-heidelberg.de; Tel: +49 621383 2614; Fax: +49621 3833806

Accepted for publication February 2002 EJA 1050
This relative hypoventilation is in contrast to ' $\alpha$-stat' management where the arterial blood is not corrected for the actual body temperature. $\alpha$-stat management (so-called alpha-stat by the constant alpha dissociation fraction of the imidazole moiety of histidine which is assumed to be responsible for a preserved enzyme and protein activity during hypothermia) mimics the unchanged ventilation of ectothermic vertebrates who do not control $\mathrm{pH}$ and temperature.

After the publication of investigations demonstrating a reduced incidence of cerebral emboli following $\alpha$-stat management during cardiac surgery $[10,11]$, it is generally accepted that lung ventilation of adults during cardiosurgical hypothermia should be adjusted using $\alpha$-stat management [12]. Since microemboli during cardiac surgery are primarily associated with the cannulation of large vessels to permit extracorporal circulation, the role of $\mathrm{pH}$ management in neurology and neurosurgery remains unclear. For hypothermic brain protection in these disciplines, until now, $\alpha$-stat management was preferred due to reports of better preservation of the coupling between CBF and metabolism in animals [13] and patients [14,15]. All cited studies measured either global metabolism (by brain arterial-venous oxygen content difference [13]) or the CBF for either the entire brain or a brain hemisphere by ${ }^{133} \mathrm{Xe}$ clearance of cerebral venous blood and argon wash-in technique, respectively. Independent variations and uncoupling of the global CBF from the global brain metabolism were demonstrated in cardiac surgical patients. Since no clinical study measured regional $\mathrm{CBF}$, the decreased metabolism - together with increased global blood flow during $\mathrm{pH}$-stat management - might have been misinterpreted as flow/metabolism mismatch. Therefore, the impact of the acid-base management on regional $\mathrm{CBF}$ and brain metabolism needs to be reconsidered.

Recently, the dose-dependent effect of hypothermia in the range $32-37.5^{\circ} \mathrm{C}$ on $\mathrm{CBF}$ and metabolism (by the local cerebral glucose utilization (LCGU)) was investigated at a local level in non-ischaemic rat brains. It became evident that local $\mathrm{CBF} /$ metabolism coupling is well preserved during hypothermia down 
Table 1. Physiological variables of the experimental groups (with permission from [16,17]).

\begin{tabular}{|c|c|c|c|c|c|}
\hline Pericranial temperature $\left({ }^{\circ} \mathrm{C}\right)$ & $37.1 \pm 0.2$ & $34.9 \pm 0.3^{*}$ & $35.0 \pm 0.1^{*}$ & $31.9 \pm 0.2^{*}$ & $31.7 \pm 0.2^{*}$ \\
\hline Arterial $\mathrm{pH}$ & $7.40 \pm 0.03$ & $7.31 \pm 0.04$ & $7.35 \pm 0.04$ & $7.34 \pm 0.03$ & $7.33 \pm 0.04$ \\
\hline $\mathrm{PaO}_{2}(\mathrm{kPa})$ & $15.2 \pm 3.7$ & $25.2 \pm 3.3^{*}$ & $25.3 \pm 3.9^{*}$ & $26.4 \pm 7.5^{*}$ & $32.9 \pm 6.4^{*}$ \\
\hline Haematocrit $(\%)$ & $43 \pm 4$ & $44 \pm 3$ & $43 \pm 6$ & $46 \pm 4$ & $44 \pm 5$ \\
\hline $\mathrm{MAP}(\mathrm{mmHg})$ & $123 \pm 12$ & $104 \pm 9^{\dagger}$ & $125 \pm 14$ & $134 \pm 18$ & $144 \pm 17^{\ddagger}$ \\
\hline Heart rate (beats $\min ^{-1}$ ) & $353 \pm 44$ & $351 \pm 36$ & $387 \pm 34$ & $367 \pm 37$ & $392 \pm 27$ \\
\hline
\end{tabular}

MAC, minimal alveolar concentration; $\mathrm{PaO}_{2}$, arterial oxygen tension; $\mathrm{PaCO}_{2}$, arterial carbon dioxide tension; MAP, mean arterial pressure. Each group: $n=10$, mean $\pm \mathrm{SD} .{ }^{*} P<0.05$ vs. normothermic controls, ${ }^{\dagger} P \leqslant 0.05$ vs. $\alpha$-stat at $32^{\circ} \mathrm{C},{ }^{\ddagger} P<0.05$ vs. $\mathrm{pH}$-stat at $35^{\circ} \mathrm{C}$.

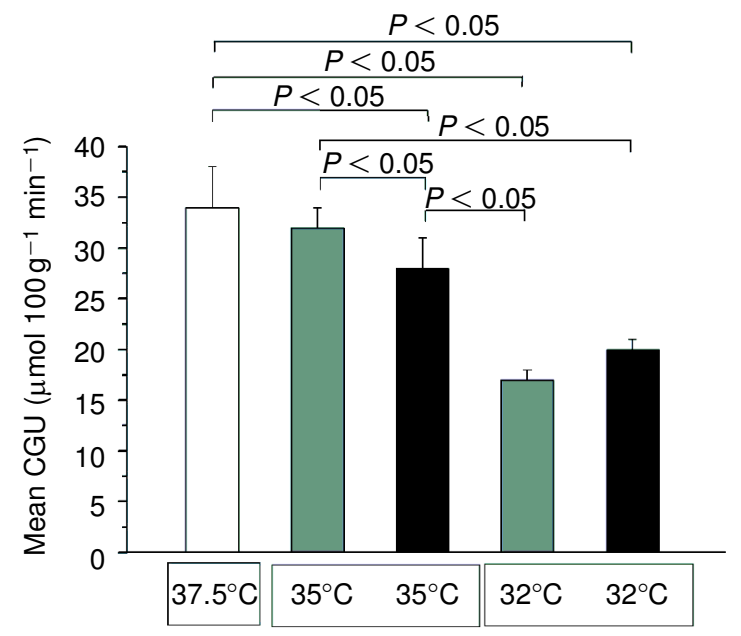

Figure 1.

Effects of the $\mathrm{pH}$ management during graded hypothermia on cerebral

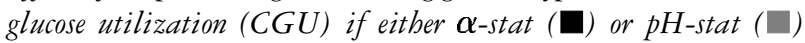
management is used (with permission from [16,17]).

to at least $32^{\circ} \mathrm{C}$ - managed by pH-stat [16] - as well as its management by $\alpha$-stat [17]. To emphasize the effect of acid-base management on $\mathrm{CBF}$ and brain metabolism under physiological conditions, $\mathrm{pH}$-stat and $\alpha$-stat data of the two latter studies were combined and compared. With the exception of an increased oxygen tension in comparison to normothermic animals, physiological variables were comparable between the groups (Table 1).

\section{Cerebral glucose utilization (or brain metabolism)}

Compared to normothermic anaesthetized controls, mean cerebral glucose utilization during mild hypothermia $\left(35^{\circ} \mathrm{C}\right)$ remained unchanged during

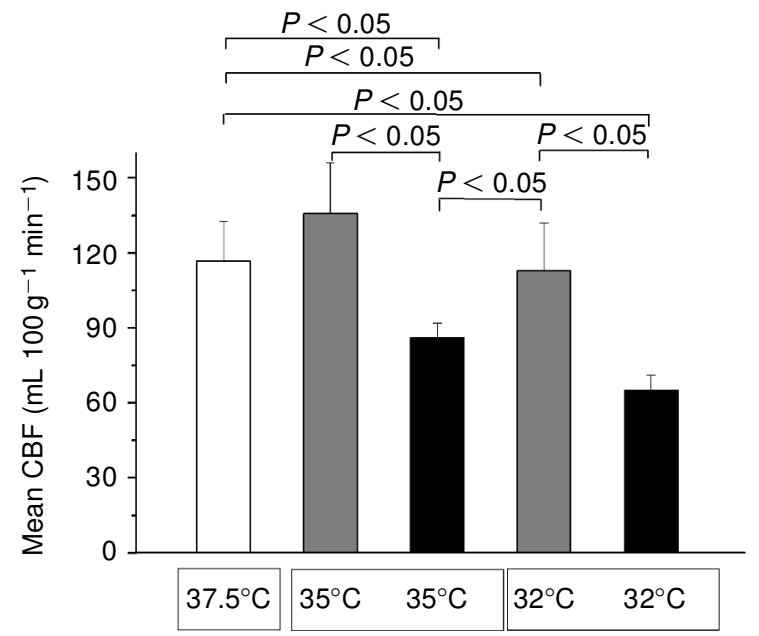

Figure 2 .

Effects of the $p H$ management during graded bypothermia on

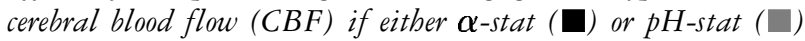
management is used (with permission from $[16,17]$ ).

$\mathrm{pH}$-stat management but was reduced during $\alpha$-stat management by $18 \%$ (Fig. 1). During $\mathrm{pH}$-stat and $35^{\circ} \mathrm{C}$, local cerebral glucose utilization was decreased only in two regions, but in 20 regions during $\alpha$-stat (Table 2). During moderate hypothermia $\left(32^{\circ} \mathrm{C}\right)$, both $\mathrm{pH}$ management reduced mean cerebral glucose utilization $(\alpha$-stat by $41 \%$ and $\mathrm{pH}$ stat by $50 \%$ ). Local cerebral glucose utilization was reduced during $\mathrm{pH}$-stat in 35 instances and during $\alpha$-stat in 32 instances out of 41 brain structures. Differences between the $\mathrm{pH}$ management on each temperature step were a lower local cerebral glucose utilization in 13 brain structures during mild hypothermia, and an increased local cerebral glucose utilization in two brain structures (cerebellar white and in the reticular part of the substantia nigra) during mild hypothermia by $\alpha$-stat treatment. 
Table 2. Local cerebral glucose utilization of the experimental groups (with permission from [16,17]).

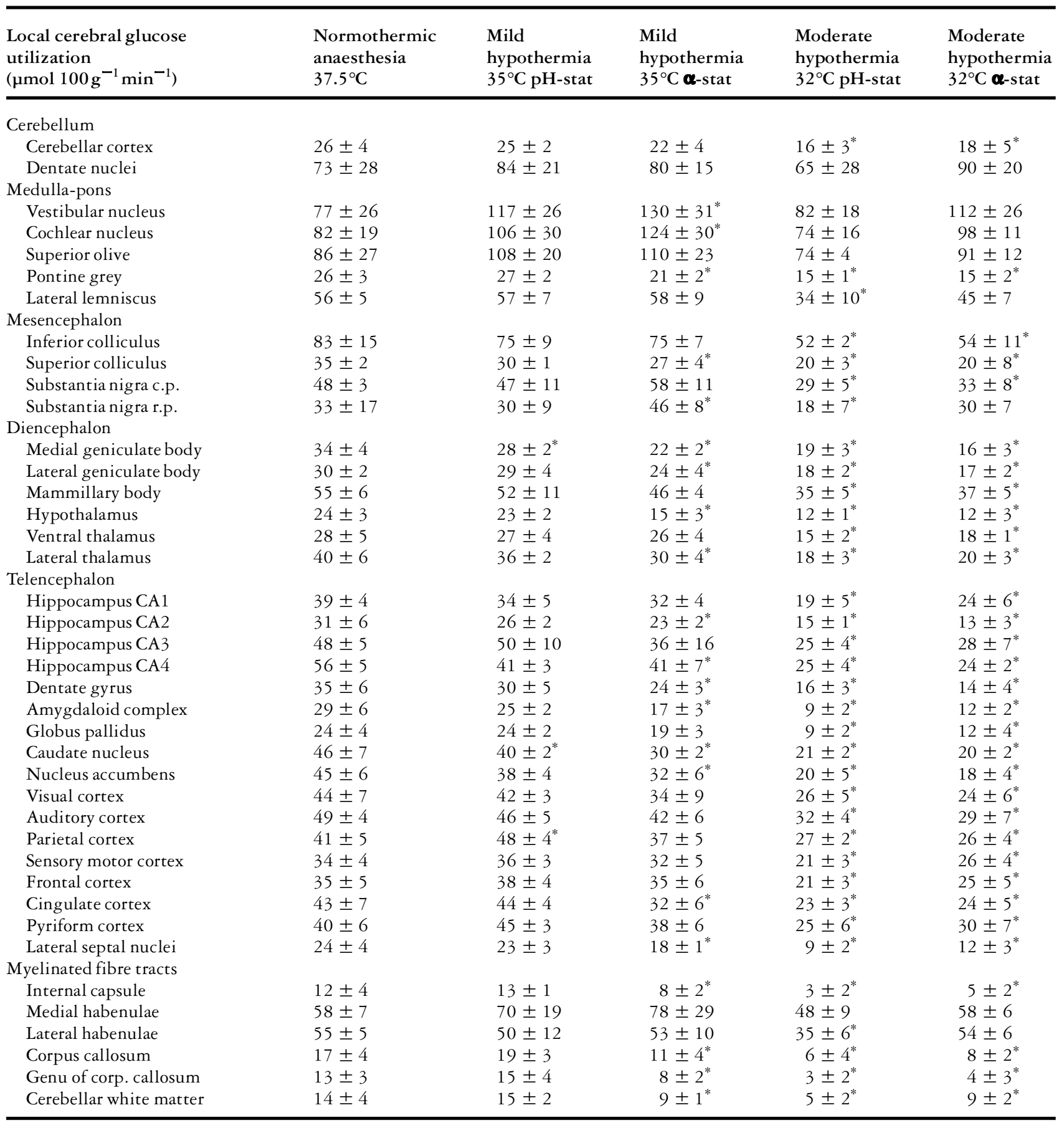

c.p.: compact part; r.p.: reticular part; corp.: corpus; each group: $n=10$, mean \pm SD. ${ }^{*} P<0.05$ vs. normothemic controls.

For differences between $\mathrm{pH}$ management, see text.

\section{Cerebral blood flow}

The mean CBF of anaesthetized controls was unchanged during $\mathrm{pH}$-stat management but was decreased in the $\alpha$-stat group by $27 \%$ during mild hypothermia $\left(35^{\circ} \mathrm{C}\right)$ and by $44 \%$ during moderate hypothermia (Fig. 2). Local cerebral blood flow was measured in 41 different brain structures (Table 3). Compared to normothermic anaesthesia, local cerebral blood flow during mild hypothermia $\left(35^{\circ} \mathrm{C}\right)$ increased in 13 brain structures with $\mathrm{pH}$-stat management but decreased in 22 structures with $\alpha$-stat management. During moderate hypothermia $\left(32^{\circ} \mathrm{C}\right)$, local $\mathrm{CBF}$ decreased in one and increased in two brain structures with $\mathrm{pH}$-stat, but decreased in 31 structures with $\alpha$-stat (Table 2). Local CBF differences between the $\mathrm{pH}$ management strategies were 
Table 3. Local cerebral blood flow of the experimental groups (with permission from [16,17]).

\begin{tabular}{|c|c|c|c|c|c|}
\hline $\begin{array}{l}\text { Cerebral blood flow } \\
\left(\mathrm{mL} 100 \mathrm{~g}^{-1} \mathrm{~min}^{-1}\right)\end{array}$ & $\begin{array}{l}\text { Normothermic } \\
\text { anaesthesia } \\
37.5^{\circ} \mathrm{C}\end{array}$ & $\begin{array}{l}\text { Mild } \\
\text { hypothermia } \\
35^{\circ} \mathrm{C} \text { pH-stat }\end{array}$ & $\begin{array}{l}\text { Mild } \\
\text { hypothermia } \\
35^{\circ} \mathrm{C} \boldsymbol{\alpha} \text {-stat }\end{array}$ & $\begin{array}{l}\text { Moderate } \\
\text { hypothermia } \\
32^{\circ} \mathrm{C} \text { pH-stat }\end{array}$ & $\begin{array}{l}\text { Moderate } \\
\text { hypothermia } \\
32^{\circ} \mathrm{C} \mathbf{\alpha} \text {-stat }\end{array}$ \\
\hline \multicolumn{6}{|l|}{ Cerebellum } \\
\hline Cerebellar cortex & $129 \pm 30$ & $169 \pm 29^{*}$ & $94 \pm 12$ & $132 \pm 29$ & $72 \pm 15^{*}$ \\
\hline Dentate nuclei & $235 \pm 56$ & $396 \pm 87^{*}$ & $206 \pm 25$ & $268 \pm 56$ & $203 \pm 45$ \\
\hline \multicolumn{6}{|l|}{ Medulla-pons } \\
\hline Vestibular nucleus & $237 \pm 45$ & $423 \pm 63^{*}$ & $312 \pm 71$ & $370 \pm 81^{*}$ & $259 \pm 37$ \\
\hline Cochlear nucleus & $272 \pm 78$ & $338 \pm 109$ & $309 \pm 74$ & $314 \pm 64$ & $210 \pm 18$ \\
\hline Superior olive & $280 \pm 52$ & $453 \pm 73^{*}$ & $285 \pm 67$ & $335 \pm 94$ & $237 \pm 47$ \\
\hline Pontine grey & $133 \pm 33$ & $180 \pm 32^{*}$ & $100 \pm 13$ & $155 \pm 16$ & $79 \pm 10^{*}$ \\
\hline Lateral lemniscus & $185 \pm 52$ & $302 \pm 43^{*}$ & $182 \pm 20$ & $216 \pm 9$ & $138 \pm 15$ \\
\hline \multicolumn{6}{|l|}{ Mesencephalon } \\
\hline Inferior colliculus & $253 \pm 43$ & $330 \pm 38^{*}$ & $180 \pm 24^{*}$ & $251 \pm 29$ & $129 \pm 15^{*}$ \\
\hline Superior colliculus & $145 \pm 23$ & $177 \pm 25$ & $98 \pm 13^{*}$ & $167 \pm 37$ & $78 \pm 13^{*}$ \\
\hline Substantia nigra c.p. & $145 \pm 15$ & $168 \pm 48$ & $83 \pm 6^{*}$ & $159 \pm 38$ & $52 \pm 31^{*}$ \\
\hline Substantia nigra r.p. & $138 \pm 17$ & $153 \pm 36$ & $82 \pm 5^{*}$ & $121 \pm 15$ & $52 \pm 31^{*}$ \\
\hline \multicolumn{6}{|l|}{ Diencephalon } \\
\hline Medial geniculate body & $156 \pm 27$ & $194 \pm 41$ & $101 \pm 10$ & $156 \pm 58$ & $76 \pm 11^{*}$ \\
\hline Lateral geniculate body & $129 \pm 27$ & $159 \pm 22^{*}$ & $91 \pm 12$ & $153 \pm 33$ & $70 \pm 6^{*}$ \\
\hline Mammillary body & $152 \pm 23$ & $213 \pm 29^{*}$ & $145 \pm 20$ & $183 \pm 32$ & $119 \pm 17$ \\
\hline Hypothalamus & $96 \pm 4$ & $105 \pm 11$ & $63 \pm 6^{*}$ & $110 \pm 19$ & $55 \pm 5^{*}$ \\
\hline Ventral thalamus & $129 \pm 25$ & $155 \pm 44$ & $65 \pm 7^{*}$ & $130 \pm 26$ & $62 \pm 10^{*}$ \\
\hline Lateral thalamus & $144 \pm 15$ & $144 \pm 30$ & $82 \pm 10^{*}$ & $153 \pm 58$ & $65 \pm 8^{*}$ \\
\hline \multicolumn{6}{|l|}{ Telencephalon } \\
\hline Hippocampus CA1 & $115 \pm 15$ & $107 \pm 18$ & $74 \pm 7^{*}$ & $116 \pm 44$ & $52 \pm 7^{*}$ \\
\hline Hippocampus CA2 & $118 \pm 30$ & $116 \pm 20$ & $70 \pm 10^{*}$ & $112 \pm 39$ & $52 \pm 6^{*}$ \\
\hline Hippocampus CA3 & $122 \pm 21$ & $144 \pm 25$ & $83 \pm 9^{*}$ & $127 \pm 39$ & $60 \pm 7^{*}$ \\
\hline Hippocampus CA4 & $135 \pm 30$ & $127 \pm 17$ & $79 \pm 3^{*}$ & $124 \pm 48$ & $57 \pm 6^{*}$ \\
\hline Dentate gyrus & $110 \pm 24$ & $114 \pm 15$ & $65 \pm 10^{*}$ & $111 \pm 36$ & $48 \pm 6^{*}$ \\
\hline Amygdaloid complex & $92 \pm 5$ & $104 \pm 20$ & $66 \pm 7^{*}$ & $106 \pm 28$ & $49 \pm 6^{*}$ \\
\hline Globus pallidus & $86 \pm 14$ & $93 \pm 22$ & $48 \pm 4^{*}$ & $80 \pm 40$ & $35 \pm 3^{*}$ \\
\hline Caudate nucleus & $134 \pm 11$ & $154 \pm 26$ & $91 \pm 9^{*}$ & $138 \pm 50$ & $66 \pm 6^{*}$ \\
\hline Nucleus accumbens & $137 \pm 11$ & $142 \pm 26$ & $79 \pm 13^{*}$ & $143 \pm 52$ & $69 \pm 7^{*}$ \\
\hline Visual cortex & $127 \pm 29$ & $153 \pm 31$ & $86 \pm 6$ & $136 \pm 42$ & $74 \pm 12^{*}$ \\
\hline Auditory cortex & $134 \pm 25$ & $158 \pm 34$ & $112 \pm 14$ & $137 \pm 42$ & $81 \pm 17^{*}$ \\
\hline Parietal cortex & $127 \pm 10$ & $142 \pm 40$ & $103 \pm 7$ & $118 \pm 46$ & $70 \pm 10^{*}$ \\
\hline Sensory motor cortex & $130 \pm 25$ & $145 \pm 39$ & $95 \pm 13$ & $138 \pm 44$ & $74 \pm 13^{*}$ \\
\hline Frontal cortex & $124 \pm 16$ & $140 \pm 13$ & $88 \pm 10$ & $128 \pm 41$ & $68 \pm 10^{*}$ \\
\hline Cingulate cortex & $147 \pm 22$ & $173 \pm 41$ & $111 \pm 8$ & $145 \pm 34$ & $81 \pm 5^{*}$ \\
\hline Pyriform cortex & $109 \pm 16$ & $165 \pm 26^{*}$ & $121 \pm 13$ & $143 \pm 39$ & $86 \pm 4$ \\
\hline Lateral septal nuclei & $104 \pm 13$ & $122 \pm 18$ & $65 \pm 11^{*}$ & $105 \pm 35$ & $52 \pm 5^{*}$ \\
\hline \multicolumn{6}{|l|}{ Myelinated fibre tracts } \\
\hline Internal capsule & $65 \pm 13$ & $68 \pm 9$ & $33 \pm 3^{*}$ & $48 \pm 21$ & $33 \pm 5^{*}$ \\
\hline Medial habenulae & $174 \pm 24$ & $219 \pm 35^{*}$ & $163 \pm 16$ & $189 \pm 32$ & $146 \pm 19$ \\
\hline Lateral habenulae & $185 \pm 33$ & $258 \pm 54$ & $166 \pm 17^{*}$ & $201 \pm 43^{*}$ & $154 \pm 10^{*}$ \\
\hline Corpus callosum & $62 \pm 17$ & $50 \pm 2$ & $31 \pm 5^{*}$ & $42 \pm 7$ & $28 \pm 3^{*}$ \\
\hline Genu of corp. callosum & $65 \pm 9$ & $68 \pm 9^{*}$ & $36 \pm 4^{*}$ & $55 \pm 19$ & $28 \pm 3^{*}$ \\
\hline Cerebellar white matter & $73 \pm 15$ & $97 \pm 11$ & $50 \pm 8$ & $69 \pm 6$ & $48 \pm 13$ \\
\hline
\end{tabular}

c.p.: compact part; r.p.: reticular part; corp.: corpus. Each group: $n=10$, mean $\pm \mathrm{SD} .{ }^{*} P<0.05$ vs. normothermic controls. For differences between $\mathrm{pH}$ management, see text.

found during mild hypothermia in all structures except for three (cochlear nuclei, hippocampus CA1, and parietal cortex). Compared to $\mathrm{pH}$-stat management, moderate hypothermia using $\alpha$-stat management was associated with a decrease in local CBF in all but five brain structures (cochlear nuclei, dentate nuclei, superior olive, internal capsule, medial habenulae).

\section{Coupling of blood flow to metabolism}

The coupling of CBF to cerebral glucose utilization was maintained during mild and moderate hypothermia with $\alpha$-stat management as shown by the relationship of local cerebral glucose utilization in each of the 41 brain regions to the local CBF in the same regions (Fig. 3) $(P>0.05)$. During pH-stat management at $35^{\circ} \mathrm{C}$ and $32^{\circ} \mathrm{C}$, the relationship 


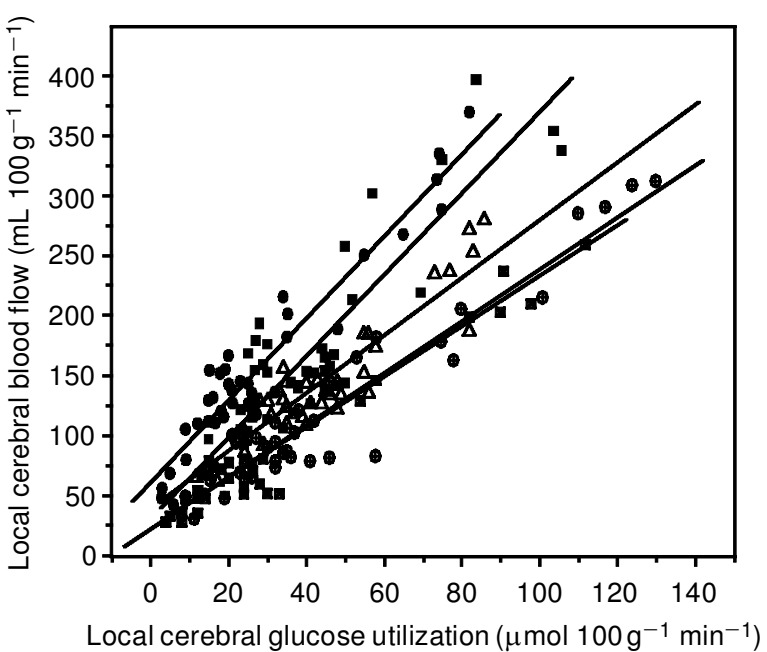

Figure 3.

Effects of the $p H$ management during graded hypothermia on the coupling of cerebral glucose utilization with cerebral blood flow if either $\boldsymbol{\alpha}$-stat $\left(35^{\circ} \mathrm{C}\right)$ and $\mathbf{\mathbb { }}\left(32^{\circ} \mathrm{C}\right)$ ) or pH-stat $\left(35^{\circ} \mathrm{C}\right)$ and $\left(32^{\circ} \mathrm{C}\right)$ ) management is used (with permission from $[16,17])$. The overall relationship between local cerebral glucose utilization (LCGU) and local cerebral blood flow (LCBF) in the examined structures of the brain was assessed by the least squares fit of the data to $y=a x+b$, where $x$ is the mean $L C G U$ in a given region, and $y$ is the mean $L C B F$ in that same area. Normothermic anaesthetized: $y=2.4 x+37.9, \quad \mathrm{r}=0.92 ; \alpha$-stat $35^{\circ} \mathrm{C}$ : $y=2.2 x+22.2, \mathrm{r}=0.95 ; \alpha$-stat $32^{\circ} \mathrm{C}: y=2.1 x+26.4$, $r=0.96 ; p H$-stat $35^{\circ} \mathrm{C}: y=3.4 x+31.6, \mathrm{r}=0.92 ; p H$-stat $32^{\circ} \mathrm{C}: y=3.4 x+62.4, \mathrm{r}=0.96$. Contrasts of slopes of the $L C B F / L C G U$ regression lines were tested by common $\mathrm{t}$-test statistics with Bonferroni correction for multiple comparisons $(\mathrm{P} \leqslant 0.05$ between the slopes of the $p H$-stat groups vs. normothermia and $p H$ stat vs. $\alpha$-stat, P $>0.05$ between the slopes of the hypothermia groups at $35^{\circ} \mathrm{C}$ and $32^{\circ} \mathrm{C}$ and both $\alpha$-stat groups vs. normothermia). Because of the limitations of this kind of analysis, an additional more rigorous statistical approach using log-transformed data was applied, examining the relationship of $L C B F$ and $L C G U$ by a repeated measure of the analysis of variance according to McCulloch et al. [23] and Ford et al. [24]. For this analysis, a computer software package (BMDP $2 v^{\circledR}$; BMDP Statistical Software Inc., Los Angeles, CA, USA) considering inter-animal variability and enabling the detection of heterogeneities in the relationship between LCGU and LCBF was used.

between local CBF and local cerebral glucose utilization was preserved but was shifted to a higher level (Fig. 3) $(P \leqslant 0.05)$. This means that, compared to normothermic anaesthesia, hypothermia and $\mathrm{pH}$-stat management reduced the local CBF less than the local cerebral glucose utilization in a brain structure. During $\alpha$-stat management, the relationship between local $\mathrm{CBF}$ and local cerebral glucose utilization is unchanged during hypothermia; this results in a reduction of local $\mathrm{CBF}$ in parallel to the local cerebral glucose utilization. In conclusion, $\mathrm{pH}$ management increases mean and local CBF but does not uncouple $\mathrm{CBF}$ from metabolism. Only the relationship of $\mathrm{CBF}$ to cerebral glucose utilization is shifted to a higher level during $\mathrm{pH}$-stat management.

\section{Is acid-base management relevant for the design of studies on hypothermic neuroprotection?}

Those results derived from experimental studies cannot be directly transferred to the clinical setting, because results were obtained from healthy animals without brain ischaemia or trauma. However, there remains the possibility that $\mathrm{pH}$-stat may be superior to $\alpha$-stat management for neuroprotection during moderate hypothermia: first, an abolished vessel reactivity to physiological stimuli appears only to occur in the ischaemic core whereas it wanes with distance in the perifocal area [18]. During the first hours, neuronal injury in this perifocal area is essentially reversible and may be salvageable. Therefore, preserved vascular reactions may, by vasodilatation, delay or even avoid the progressive metabolic deterioration of the penumbra and the enlargement of the dense ischaemia zone. Working on both metabolism increase and perfusion decrease, hypothermia should be better combined with an increase in $\mathrm{CBF}$ during $\mathrm{pH}$-stat than the reduction observed during $\alpha$-stat management. Another potential mechanism - in addition to better cerebral oxygenation - might be that an increased or maintained CBF itself might result in a more homogenous temperature profile throughout the brain [19] thus counteracting the considerable temperature gradient in ischaemic brain [20]. Moreover, it is well known that experimental hypothermic neuroprotection depends not only upon reduced metabolism but on several other factors such as the release of neurotoxic mediators or the integrity of the blood-brain barrier [21]. At least in modestly perfused tissues, e.g. the penumbra, one can speculate that these toxic mediators are eliminated more efficiently by a higher blood flow. On the other hand, a preserved or even an increased $\mathrm{CBF}$ has to be avoided so as not to reach a critically raised intracranial pressure (ICP). However, ICP elevations in brain trauma [4] and severe stroke [22] are less frequent during hypothermia than during normothermia.

In conclusion, $\mathrm{pH}$ management does not uncouple $\mathrm{CBF}$ from metabolism but $\mathrm{pH}$-stat management shifts the relationship of $\mathrm{CBF}$ to cerebral glucose utilization to a higher level. Relevant clinical outcome studies on the effect of the acid-base management during hypothermia on ischaemia or brain injury are lacking. As long as they do not exist, the $\mathrm{pH}$-management used in studies for neuroprotective 
hypothermia needs to be carefully considered to avoid further controversial results.

\author{
T. Frietsch \\ Department of Anaesthesiology and \\ Critical Care Medicine \\ Faculty of Clinical Medicine Mannheim \\ University of Heidelberg, Germany
}

A. Piepgras

Department of Neurosurgery

Faculty of Clinical Medicine Mannheim

University of Heidelberg, Germany

$$
\begin{array}{r}
\text { P. Krafft } \\
\text { Department of Anaesthesiology } \\
\text { University of Vienna, Austria }
\end{array}
$$

\section{S. Schwab \\ Department of Neurology \\ Faculty of Clinical Medicine Heidelberg \\ University of Heidelberg, Germany}

W. Kuschinsky
Department of Physiology and Pathophysiology
University of Heidelberg, Germany

K. F. Waschke

Department of Anaesthesiology and

Critical Care Medicine

Faculty of Clinical Medicine Mannheim

University of Heidelberg, Germany

\section{References}

1. Mild therapeutic hypothermia to improve the neurologic outcome after cardiac arrest. N Engl J Med 2002; 346: 549-556.

2. Xiao F, Zhang S, Arnold TC, et al. Mild hypothermia induced before cardiac arrest reduces brain edema formation in rats. Acad Emerg Med 2002; 9: 105-114.

3. Bernard SA, Gray TW, Buist MD, et al. Treatment of comatose survivors of out-of-hospital cardiac arrest with induced hypothermia. N Engl J Med 2002; 346: 557-563.

4. Clifton GL, Miller ER, Choi SC, et al. Lack of effect of induction of hypothermia after acute brain injury. $N$ EnglJ Med 2001; 344: 556-563.

5. Clifton GL, Choi SC, Miller ER, et al. Intercenter variance in clinical trials of head trauma - experience of the National Acute Brain Injury Study: Hypothermia. J Neurosurg 2001; 95: 751-755.

6. Safar P, Kochanek PM. Lack of effect of induction of hypothermia after acute brain injury. N Engl J Med 2001; 345: 66

7. Sakas DE, Dimopoulou I. Lack of effect of induction of hypothermia after acute brain injury. N Engl J Med 2001; 345: 66.
8. Safar PJ, Kochanek PM. Therapeutic hypothermia after cardiac arrest. N Engl J Med 2002; 346: 612-613.

9. Curfman GD. Hypothermia to protect the brain. N Engl $J$ Med 2002; 346: 546

10. du Plessis AJ, Jonas RA, Wypij D, et al. Perioperative effects of alpha-stat versus $\mathrm{pH}$-stat strategies for deep hypothermic cardiopulmonary bypass in infants. $J$ Thorac Cardiovasc Surg 1997; 114: 991-1000.

11. Jonas RA, Bellinger DC, Rappaport LA, et al. Relation of $\mathrm{pH}$ strategy and developmental outcome after hypothermic circulatory arrest.J Thorac Cardiovasc Surg 1993; 106: 362-368.

12. Hindman $\mathrm{BJ}$. Choice of alpha-stat or $\mathrm{pH}$-stat management and neurologic outcomes after cardiac surgery: it depends. Anesthesiology 1998; 89: 5-7.

13. Hindman BJ, Dexter F, Cutkomp J, Smith T, Tinker JH. Hypothermic acid-base management does not affect cerebral metabolic rate for oxygen at 27 degrees C. A study during cardiopulmonary bypass in rabbits. Anesthesiology 1993; 79: 580-587.

14. Murkin JM, Farrar JK, Tweed WA, McKenzie FN, Guiraudon G. Cerebral autoregulation and flow/metabolism coupling during cardiopulmonary bypass: the influence of $\mathrm{PaCO}_{2}$. Anesth Analg 1987; 66: 825-832.

15. Stephan H, Weyland A, Kazmaier S, Henze T, Menck S, Sonntag H. Acid-base management during hypothermic cardiopulmonary bypass does not affect cerebral metabolism but does affect blood flow and neurological outcome. BrJ Anaesth 1992; 69: 51-57.

16. Frietsch T, Krafft P, Piepgras A, Lenz C, Kuschinsky W, Waschke KF. Relationship between local cerebral blood flow and metabolism during mild and moderate hypothermia in rats. Anesthesiology 2000; 92: 754-763.

17. Krafft P, Frietsch T, Lenz C, Piepgras A, Kuschinsky W, Waschke KF. Mild and moderate hypothermia (alpha-stat) do not impair the coupling between local cerebral blood flow and metabolism in rats. Stroke 2000; 31: 1393-1401.

18. Dirnagl U, Iadecola C, Moskowitz MA. Pathobiology of ischaemic stroke: an integrated view. Trends Neurosci 1999; 22: 391-397.

19. Kurth CD, O'Rourke M, O'Hara I. Comparison of $\mathrm{pH}$-stat and alpha-stat cardiopulmonary bypass on cerebral oxygenation and blood flow in relation to hypothermic circulatory arrest in piglets. Anesthesiology 1998; 89: 110-118.

20. Schwab S, Spranger M, Aschoff A, Steiner T, Hacke W. Brain temperature monitoring and modulation in patients with severe MCA infarction. Neurology 1997; 48: 762-767.

21. Schwab M, Bauer R, Zwiener U. Mild hypothermia prevents the occurrence of cytotoxic brain edema in rats. Acta Neurobiol Exp 1998; 58: 29-35.

22. Schwab S, Schwarz S, Aschoff A, Keller E, Hacke W. Moderate hypothermia and brain temperature in patients with severe middle cerebral artery infarction. Acta Neurochir Suppl 1998; 71: 131-134.

23. McCulloch J, Kelly PA, Ford I. Effect of apomorphine on the relationship between local cerebral glucose utilization and local cerebral blood flow (with an appendix on its statistical analysis). J Cereb Blood Flow Metab 1982; 2: 487-499.

24. Ford I, McColl JH, McCormack AG, McCrory SJ Statistical issues in the analysis of neuroimages. $J$ Cereb Blood Flow Metab 1991; 11: A89-A95. 